\title{
Necessidades em(de) saúde: conceitos, implicações e desafios para o Sistema Único de Saúde
}

\author{
Needs in health/health needs: concepts, implications and challenges \\ for the Brazilian Unified Health System
}

Leonardo Carnut', Camila Biancchi Ferraz ${ }^{\mathbf{2}}$

DOI: $10.1590 / 0103-1104202112916$

RESUMO Este estudo revisou sistematicamente a literatura sobre 'necessidades em(de) saúde'. Tratou-se de uma revisão integrativa utilizando o portal Biblioteca Virtual em Saúde. Português, espanhol e inglês foram os idiomas utilizados e recuperaram-se apenas os textos completos e com foco específico no Sistema Único de Saúde. Totalizaram-se 17 artigos incluídos, dos quais 88,8\% estavam indexados na base Literatura Latino-Americana e do Caribe em Ciências da Saúde. Há uma variada forma de apropriação das 'necessidades em(de) saúde', termo cuja definição não é bem delimitada pelos autores, direcionando-o a três núcleos de sentido: 'direito social constituído', 'conjunto articulado da efetividade dos direitos sociais' e 'ajuste entre as condições de vida e trabalho com a diversidade inerente às coletividades'. Diversas implicações para o Sistema Único de Saúde foram apresentadas e puderam ser compiladas em sete blocos: 'capitalismo e sua crise', 'financiamento', 'características da formação social brasileira', 'problemas da gestão pública na saúde', 'mescla público-privado', 'problemas terminológicos' e 'escassez de recursos'. Por fim, os principais desafios da aplicação das necessidades no Sistema Único de Saúde transitam entre o simbólico, o crítico-político, a coerência entre financiamento-princípios, o Estado, a política macroeconômica, a gestão e as ações locais. Investir na superação dos desafios elencados pode ser um guia para a efetivação das necessidades como o centro da ação sanitária.

PALAVRAS-CHAVE Sistema Único de Saúde. Financiamento da assistência à saúde. Direito à saúde. Política de saúde. Equidade na alocação de recursos.

ABSTRACT This study reviewed systematically the literature on 'needs in health/health needs'. This was an integrative review using the Virtual Health Library portal. Portuguese, English and Spanish were the languages used and only the full texts were recovered with a specific focus on the Unified Health System. A total of 17 articles were included, of which $88.8 \%$ were indexed in the Latin American and Caribbean Health Sciences database. There is a varied form of appropriation of the theme 'needs in health/health needs', a very broad concept whose definition is not well delimited by the authors, directing it to three nuclei of meaning: 'constituted social right', 'articulated set of the effectiveness of social rights' and 'adjustment between living and working conditions with the inherent diversity of collectivities'. Several implications for the Unified Health System were presented and could be compiled in seven blocks: 'capitalism and its crisis', 'financing', 'characteristics of the Brazilian social formation', 'problems of public health management', 'public-private mix', 'terminological problems' and 'scarcity of resources'. Finally, the main

1 Universidade Federal de São Paulo (Unifesp) - São Paulo (SP), Brasil. leonardo.carnut@gmail.com

2 Universidade de São Paulo (USP) - São Paulo $(\mathrm{SP})$, Brasil. challenges of applying the needs in the Unified Health System move between the symbolic, the critical-political, the coherence between financing-principles, the State, macroeconomic policy, management and local actions. Investing in overcoming the challenges listed can be a guide in realizing needs as the center of health action.

KEYWORDS Unified Health System. Healthcare financing. Right to health. Health policy. Equity in the resource allocation. 


\section{Introdução}

Com a promulgação da Lei $\mathrm{n}^{\circ} 141 / 2012$, o debate sobre a delimitação concreta do que vêm a ser 'necessidades' no setor saúde ganhou novo fôlego. Contudo, sua precisão conceitual ainda permite diversas interpretações, o que, em tempos de crise do capital, tem sido terreno fértil para confundir desejos com necessidades. Neste caminho, ao definir 'necessidades humanas básicas', Gomes Júnior e Pereira ${ }^{1}$ ajudam a esclarecer que a saúde é pré-condição para a libertação do ser humano e, neste sentido, o que é necessário para ter saúde pode até não ser consensual, mas certamente é básico ao construto humano. Sendo assim, pode-se dizer que, para estes autores, a maneira como se vive traduz-se em diferentes 'necessidades de saúde', e suas formas de expressão estão totalmente vinculadas às exigências, não apenas biológicas, mas sociais da vida em coletividade ${ }^{2}$.

Por isso, vale a pena tornar mais clara a diferença entre 'necessidades em saúde' e 'necessidades de saúde'. A literatura científica brasileira ainda é imprecisa sobre o assunto ${ }^{3}$. Mesmo assim, o mínimo que se pode apontar é que o 'social' está oculto no termo. Quando se fala em 'necessidades em saúde', refere-se, como descrito por Almeida-Filho e Paim ${ }^{4}$, ao objeto da 'nova saúde pública', grosso modo incorporada no Brasil sob o rótulo de 'Saúde Coletiva'. Trata-se, portanto, da expressão do 'social' na saúde, ou seja, de como as condições políticas, econômicas, ambientais e educacionais, entre tantas outras da organização das sociedades, são responsáveis pela geração de saúde-doença nas populações.

Nesse sentido, pode-se afirmar que, ao empregar o termo 'necessidades em saúde', pretende-se ressaltar a compreensão de um 'elo', de uma 'conexão intrínseca', ou, em palavras mais certeiras, de um 'processo de determinação'4 . A proposta original era não tratar as necessidades em saúde como uma relação de exposição-desfecho unicausal, e sim como a síntese de múltiplas determinações, nas quais o 'social' e seus (re)arranjos produtivos são a base para compreender o padrão de salubridade-adoecimento de uma sociedade'.

Em contrapartida, em termos de 'necessidades de saúde', parece haver um leque mais amplo de significados ${ }^{2}$. A diferença pode ser de grau, mas ela existe. Este termo sugere tratar, portanto, das múltiplas dimensões em que os diversos segmentos sociais e interessados na discussão (usuários, grupos específicos, gestores, pesquisadores, técnicos, profissionais de saúde etc.) compreendem o que é necessário para ter saúde a partir de seus repertórios, isto podendo transitar entre um espectro de possibilidades, que vai desde o 'acesso aos serviços de saúde' até o simplesmente 'ser feliz'.

Por isso que quem emprega o termo 'necessidades de saúde' parece estar mais focado em operacionalizar tais necessidades ${ }^{2}$. Quem utiliza o termo está preocupado em como medi-las, como torná-las quantificáveis e como garantir a adequabilidade necessária entre quem necessita e quem deve ofertar. Neste sentido, o que subjaz este termo, em última instância, é a preocupação com o elo entre o planejamento e a alocação de recursos, em uma perspectiva equânime.

Mesmo com essa tentativa de elucidar as diferenças existentes entre os dois termos, é necessário reafirmar que eles são totalmente interdependentes. Por isto que, quando se fala em 'necessidade em(de) saúde', deve-se considerar que tais necessidades são humanas e, portanto, são o que sustenta a ideia de que o seu atendimento adequado pertence à esfera da vida em coletivos humanos. No que tange aos marcos da modernidade, especialmente àqueles cunhados pela filosofia política liberal, cabe aos Estados o dever de assegurar o direito à vida dos indivíduos, o que, em termos de operacionalidade, se constituiu na formulação das políticas sociais ${ }^{1}$.

Especialmente sobre o direito à vida como um direito social, disposto no art. $6^{\circ}$ da Constituição Federal de $1988^{5}$, seus moldes se conformam sob a lógica de uma atenção integral, que, em primazia, deveria ser para todos, 
por um lado; por outro lado, vem sendo modelado como uma estratégia de mercantilização no cotidiano dos serviços, e - por que não dizer? -, um simulacro da reprodução dos interesses do grande capital, conforme pode ser conferido nos documentos do Banco Mundial6-8.

Considerando que essa forma de reprodução pode ser entendida como a 'necessidade básica' para o capital e sua sustentabilidade é que a mercantilização da saúde vem se tornando um elemento estratégico de sua sobrevivência, explicitando o conflito entre necessidades humanas básicas (das quais as 'necessidades em(de) saúde' fazem parte) e as necessidades do capital1,7. É sob esta contradição que o foco deste estudo retoma uma das necessidades humanas essenciais, garantidora da existência dos seres humanos, que é a 'necessidade em(de) saúde'.

Logo, o objetivo deste artigo é revisar sistematicamente a literatura científica sobre necessidades em(de) saúde, suas implicações e desafios para o Sistema Único de Saúde (SUS).

\section{Material e métodos}

Tratou-se de uma revisão integrativa ${ }^{9,10}$, cujo objetivo foi revisar, de forma sistematizada, a literatura científica sobre necessidades de saúde, e sua aplicação no SUS. Para isso, dois objetivos guiaram a extração dos dados dos artigos incluídos nesta revisão: 1) Identificar os termos 'necessidade em(de) saúde', suas implicações e desafios para a construção do SUS; e 2) Discutir o contexto de análise dos termos e a ligação/nexo entre necessidade em(de) saúde e necessidades do capital.

Nesse sentido, a primeira etapa consistiu em um procedimento de busca sistematizada nas bases de dados que indexam estudos nessa temática. Assim, elegeu-se o portal de informação científica da Biblioteca Virtual em Saúde (BVS) (www.bvsalud.org) como aquele que aglutina diversas bases de dados da América Latina e do Caribe, para coletar os dados relacionados ao tema, de acordo com a pergunta norteadora da busca: $\mathrm{O}$ que a literatura científica apresenta sobre as necessidades em(de) saúde no SUS?

Os descritores eleitos foram derivados da pergunta de pesquisa. Nesse sentido, foram buscados aqueles que convergissem à ideia de necessidades, capitalismo e sistema de saúde, na mesma definição explicativa do descritor. Tal estratégia requereu não considerar descritores como 'Determinação de Necessidades de Cuidados de Saúde' e 'Necessidades e Demandas de Serviços de Saúde' na organização da sintaxe de busca, por não congregarem esses três elementos. Além disto, houve uma preocupação exaustiva em realizar os testes de cruzamento de descritores em diversas possibilidades (usando os operadores booleanos AND e OR), para eleger as buscas com maior número de recuperação, visando construir uma sintaxe final.

A partir desses descritores e de diversas formas de testagem, gerou-se a seguinte sintaxe final: (mh:((("Sistema Único de Saúde" AND "Financiamento da Assistência à Saúde" AND "Direito à Saúde")))) OR (mh:((("Sistema Único de Saúde" AND "Financiamento da Assistência à Saúde" AND "Política de Saúde")))) OR (mh:((("Sistema Único de Saúde" AND "Financiamento da Assistência à Saúde" AND "Equidade na alocação de recursos”)))) OR (mh:((“Sistema Único de Saúde" AND "Direito à Saúde” AND "Política de Saúde")))) OR (mh:((("Sistema Único de Saúde" AND "Direito à Saúde" AND "Capitalismo")))) OR (mh:((("Sistema Único de Saúde" AND "Política de Saúde" AND "Equidade na alocação de recursos")))) OR (mh:((“Sistema Único de Saúde” AND "Política de Saúde" AND “Capitalismo")))).

Essa sintaxe redundou na identificação de 140 estudos (testada em 16 de junho de 2019). Foram incluídos somente trabalhos com o texto completo disponível gratuitamente e com foco específico no SUS e na questão levantada na pesquisa. Não houve restrição quanto à data de publicação. Apenas publicações em português, espanhol e inglês foram consideradas. Como 
critério de exclusão, foram desconsiderados livros, capítulos de livros, editoriais e outros formatos de texto que não passaram por processo rigoroso de avaliação por pares, como ocorre com os artigos científicos.

Do total, apenas 65 estavam disponíveis na íntegra, sendo a primeira etapa de seleção das produções realizada mediante a leitura e a análise dos títulos e resumos. Entre eles, havia cinco estudos repetidos, 11 monografias, oito produções diversas (livros, revistas, cursos e vídeos institucionais), e tais publicações não compuseram o escopo final por não se apresentarem em formato de artigo científico. Após essa triagem inicial, na segunda etapa, procedeu-se à leitura na íntegra dos 41 estudos selecionados, a qual possibilitou que outros textos também fossem excluídos por não atenderem à proposta da revisão. Ao final, 17 artigos científicos foram incluídos na revisão, disponíveis gratuitamente, tendo atendido aos critérios estabelecidos.

A partir da identificação das bases de dados, confirmação da disponibilidade gratuita dos estudos e de sua filtragem pelos critérios estabelecidos, os artigos incluídos foram lidos na íntegra. Nessa leitura, foram extraídos dos artigos os seus achados, segundo o interesse de investigação desta revisão (conceitos de 'necessidades em(de) saúde', suas implicações e seus desafios para o SUS).

\section{Resultados}

Os artigos desta revisão foram coletados através do portal BVS e apresentaram a seguinte distribuição, por banco de dados de indexação: a maior parte dos estudos (16) encontra-se indexada na base de dados Lilacs $(88,9 \%)$ e apenas um na Base de Dados de Enfermagem (BdEnf) (5,6\%). É possível identificar que $11(64,7 \%)$ artigos se utilizam do método de revisão narrativa; 8 (47,05\%) apresentam alguma referência sobre 'necessidades em(de) saúde'; 14 (82,35\%) apresentam a importância relacionada às 'necessidades em(de) saúde'; $\mathrm{e}$
15 (88,23\%) discorrem sobre os desafios para sua aplicação no SUS. Estes últimos artigos, apesar de discutirem o financiamento da política de saúde no Brasil, o financiamento da atenção básica e a relação saúde-direito, apresentavam a relação de seus objetos com o conceito de 'necessidade em(de) saúde' e, por esse motivo, foram adicionados à análise.

Foi possível perceber que há variadas formas de apropriação da temática 'necessidade em(de) saúde', e que, por este ser um conceito muito amplo, diversos estudos não delimitam bem sua definição, que varia desde a mera citação do termo, sem descrição/conceituação alguma, até seu uso mais refinado e sua identificação/conceitualização mais precisa em práticas e relatos de experiências nos serviços de saúde.

Nos textos dos autores que, de certa maneira, apenas 'tangenciam' o tema ${ }^{6,8,11-17}$, o termo 'necessidade em(de) saúde' não aparece, porém, no decorrer da leitura, pode-se perceber que as discussões são baseadas nas necessidades, implicações para o SUS e nos desafios de sua aplicação. Outros, por sua vez ${ }^{\mathbf{1 8 - 2 5}}$, citam o termo e o conceitualizam, mas em nenhum deles o termo 'necessidades em(de) saúde' aparece como um indexador.

É interessante notar que há um refino da ideia de necessidades em(de) saúde nesses estudos. Em alguma medida, fica explícito que a concepção das necessidades parte de uma ideia geral (como direito social) em direção a uma perspectiva mais aplicada (considerando as diferentes condições de vida da população). Em que pese a relativa falta de definição apresentada nos estudos, estas formas de apropriação teórico-metodológica das necessidades em(de) saúde parecem ser elementos fecundos para discutir sua relação com as necessidades do capital.

Ao buscar compreender como os estudos relacionam o conceito sobre necessidades em(de) saúde com as implicações para o SUS, fica evidente que, mesmo aqueles que não desenvolvem o conceito, estão se preocupando com a ideia de necessidades. Não obstante, 
é possível ver que há mais estudos que trazem consigo as implicações do que aqueles que delimitam claramente as necessidades em(de) saúde. O mesmo acontece em relação aos desafios, demonstrando que os artigos que versam sobre estes tentam direcionar soluções para que os serviços e sistemas de saúde alcancem as necessidades em(de) saúde, sugerindo propostas, conforme pode ser visto no quadro 1 . Os polos de análise, núcleos de sentido e blocos de análise que emergiram da sistematização dos conteúdos dos artigos podem ser vistos no quadro 2 .

Quadro 1. Artigos incluídos e respectiva metodologia, conceito de 'necessidades em(de) saúde', implicações para o SUS e os principais desafios de sua aplicação no SUS

\begin{tabular}{llll}
\hline Autores/Ano & Metodologia & $\begin{array}{l}\text { O que são 'necessidades } \\
\text { em(de) saúde'? }\end{array}$ & Implicações para o SUS \\
\hline Cohn, 2018 & $\begin{array}{l}\text { Revisão nar- } \\
\text { rativa }\end{array}$ & $\begin{array}{l}\text { Não apresenta um conceito } \\
\text { sobre necessidades em saúde. }\end{array}$ & $\begin{array}{l}\text { Contexto crescentemente desfa- } \\
\text { vorável, em termos de: políticas } \\
\text { econômicas (ajuste fiscal); difi- } \\
\end{array}$ \\
& & $\begin{array}{l}\text { culdades impostas por um Estado } \\
\text { patrimonialista e uma sociedade }\end{array}$ \\
& & conservadora; e aversão a medidas \\
& & equitativas dos recursos sociais.
\end{tabular}

Pinto, 2018 Estudo descritivo analítico, revisão de literatura

Miranda,

Mendes e

Silva, 2017

Entrevista semiestruturada e revisão crítica da literatura

Barros e Revisão narSousa, 2016 rativa

Rizzotto e Campos, Revisão nar2016
A adequação do financiamento às condições, especificidades e aos projetos locais dos municípios.

Não apresentam um conceito sobre necessidades em saúde.

As diferenças entre os distintos grupos sociais, que são determinadas pelas diversidades de sexo, idade e raça, e por situações de injustiça social, como renda e acesso a bens e serviços, e, ainda, por características culturais e subjetivas de grupos e indivíduos.

Não apresentam um conceito sobre necessidades em saúde.
Não apresenta implicações para o SUS.

Organização e fragmentação das políticas; insuficiente financiamento; complexas relações entre a esfera pública e o mercado; fragilidades nos processos regulatórios; e desigualdades em saúde, que permanecem e que marcam a sociedade brasileira.

Que a equidade seja concebida na perspectiva ética e da justiça, diante das históricas iniquidades presentes na sociedade brasileira, agravadas pela globalização.

O direito universal à saúde não faz parte do ideário liberal e também não é mencionado nos princípios filosóficos do Banco Mundial. Regular a oferta e garantir 'mínimos essenciais' devem ser tarefas do Estado, contudo, este organiza um aparato público reduzido, que desenvolve a desestruturação das necessidades, padronizando-as em função do mercado.
Conclusões e desafios de sua aplicação no SUS

A questão da saúde sensibiliza e mobiliza segmentos da sociedade, mas, exatamente por demandar que se vá além da saúde como consumo ou acesso a serviços e tecnologias de diagnóstico e terapêutica, esbarra na relativa fragilidade para se constituir isoladamente em fator de organização e mobilização social.

Não apresenta desafios relacionados à aplicação no SUS.

Criar espaços de discussão dos principais aspectos que dificultam a consolidação do SUS; estudar as responsabilidades sanitárias e o papel das esferas de governo; e planejar políticas que superem os desafios atuais e futuros, assegurando o direito social do cidadão de acesso universal à saúde.

Equidade horizontal, ou seja, acesso, utilização e tratamento igual para necessidades iguais. Deve-se considerar a equidade como estratégia para atingir a igualdade de oportunidades, levando em conta as disparidades de ordem social, étnica, econômica e cultural. Ela poderá ser mensurada através da análise das políticas públicas, no setor da saúde, vendo o necessário a todos, levando em conta singularidades e necessidades.

As crises de acumulação têm levado o capital a expandir-se para todos os espaços da vida social. O SUS é um experimento que, na perspectiva do Banco Mundial, não deve se expandir para outros países da América Latina e mesmo para o mundo, na medida em que garante, constitucionalmente, o direito universal à saúde. 


\begin{tabular}{lll}
\hline Autores/Ano & Metodologia & $\begin{array}{l}\text { O que são 'necessidades } \\
\text { em(de) saúde'? }\end{array}$ \\
\hline $\begin{array}{l}\text { Mendes, } \\
2015\end{array}$ & $\begin{array}{l}\text { Revisão nar- } \\
\text { rativa }\end{array}$ & $\begin{array}{l}\text { Não apresenta um conceito } \\
\text { sobre necessidades em saúde. }\end{array}$
\end{tabular}

Araujo, 2015 Revisão crítica da literatura

As condições de alimentação, habitação, educação, renda, meio ambiente, transporte, emprego, lazer, liberdade, acesso e posse da terra, e acesso a serviços de saúde.

Silva e Junior,

Mendes e Revisão narLouvison, rativa 2015

Mendes 2013

Revisão nar-

Merhy, 2012 Revisão narrativa rativa

Pesquisa com Conjunto de práticas democratiobservação dire- zantes que 'integram a totalidade ta e entrevista social', noção de direito à saúde, que implica, entre outros fatores, a garantia de trabalho, alimentação, moradia, transporte, lazer e participação da população na organização, gestão e controle dos serviços, além de um acesso universal e igualitário, em todos os níveis.

Não apresentam um conceito sobre necessidades em saúde.

A nova 'universalidade' é compreendida como uma cesta básica de serviços para a população pobre, restando o acesso aos demais serviços de saúde pela via do mercado.

Não apresenta um conceito sobre necessidades em saúde.

A dificuldade de acesso e o problema do financiamento.

Não apresenta implicações para o SUS.
Conclusões e desafios de sua aplicação no SUS

O desafio reside em equalizar o crescimento econômico e manter o patamar de investimento em políticas sociais de direitos, priorizando o financiamento do SUS.

A saúde tem sido alvo de políticas restritivas, expressas por ações como o subfinanciamento e a privatização dos serviços, desde seu nascedouro, bem como por meio das novas modalidades de gestão propostas para o serviço público, com as Organizações Sociais e outras, refletindo a lógica neoliberal do Estado.

A descentralização das decisões pela municipalização e um maior acesso à rede de serviços não cumprem a universalidade, equidade e qualidade no acesso à saúde. As políticas macroeconômicas isentam o Estado de seu papel na efetivação dos direitos.

O acesso aos serviços locais está estrangulado em sua capacidade de avanço e de promoção de integralidade e de equidade, por não ser construído solidariamente. Além disso, apesar da determinação de mecanismos de alocação equitativa de recursos das transferências do governo federal para os municípios, pela Lei no 141/2012, não se conseguiu definir, até o momento, critérios baseados em necessidades de saúde.

Olhar crítico e denso sobre o conflituoso caminho de consolidação do direito à saúde no Brasil - inserida no cenário de constrangimentos da saúde universal -, acirrado pelos problemas de financiamento e gestão do SUS.

Concepção da radicalidade necessária para pensar o que seria a construção de um campo social de práticas, democrático. Dilema do perspectivismo de um 'SUS-utopia', tem que negociar com isto e reconhecer, na molecularidade do fazer, modelos centralizadores e antivida das políticas governamentais. 
Quadro 1. (cont.)

\begin{tabular}{|c|c|c|c|c|}
\hline Autores/Ano & Metodologia & $\begin{array}{l}\text { O que são 'necessidades } \\
\text { em(de) saúde'? }\end{array}$ & Implicações para o SUS & $\begin{array}{l}\text { Conclusões e desafios de sua aplicação } \\
\text { no SUS }\end{array}$ \\
\hline $\begin{array}{l}\text { Mendes e } \\
\text { Marques, } \\
2009\end{array}$ & $\begin{array}{l}\text { Revisão nar- } \\
\text { rativa }\end{array}$ & $\begin{array}{l}\text { Não apresentam um conceito } \\
\text { sobre necessidades em saúde. }\end{array}$ & $\begin{array}{l}\text { O principal inimigo da saúde pú- } \\
\text { blica é o grande capital financeiro, } \\
\text { com seus efeitos no corte dos re- } \\
\text { cursos para a área social, em geral, } \\
\text { e para a saúde, em particular. }\end{array}$ & $\begin{array}{l}\text { Garantir o 'princípio da construção da } \\
\text { universalidade', por meio da defesa per- } \\
\text { manente de recursos financeiros seguros. }\end{array}$ \\
\hline $\begin{array}{l}\text { Baptista, } \\
\text { Machado e } \\
\text { Lima, } 2009\end{array}$ & $\begin{array}{l}\text { Revisão nar- } \\
\text { rativa }\end{array}$ & $\begin{array}{l}\text { Saúde como direito social de } \\
\text { cidadania e um conjunto inte- } \\
\text { grado de ações de bem-estar e } \\
\text { justiça social. }\end{array}$ & $\begin{array}{l}\text { Restrições ao exercício de respon- } \\
\text { sabilidade da atuação do Estado } \\
\text { na garantia da saúde como direito } \\
\text { de cidadania: os obstáculos à } \\
\text { consolidação da Seguridade Social; } \\
\text { o instável aporte de recursos finan- } \\
\text { ceiros; a insuficiente provisão de } \\
\text { insumos relevantes para a saúde, } \\
\text { como medicamentos; a fragilidade } \\
\text { das políticas de recursos humanos } \\
\text { em saúde; e a persistência de dis- } \\
\text { torções nas relações entre público } \\
\text { e privado na saúde. }\end{array}$ & $\begin{array}{l}\text { Permanece como grande desafio do } \\
\text { Estado, entendido de forma ampla, para } \\
\text { garantir a democracia e exercer o papel } \\
\text { mediador de interesses e demandas, } \\
\text { estabelecendo prioridades e atuando de } \\
\text { forma equilibrada, visando ao bem estar } \\
\text { coletivo e não simplesmente atendendo } \\
\text { aos interesses de grupos específicos. }\end{array}$ \\
\hline $\begin{array}{l}\text { Gonçalves et } \\
\text { al., } 2007\end{array}$ & $\begin{array}{l}\text { Revisão crítica } \\
\text { da literatura }\end{array}$ & $\begin{array}{l}\text { Alimentar-se adequadamente, } \\
\text { ter condições dignas de mora- } \\
\text { dia, direito ao trabalho e a ho- } \\
\text { ras de lazer. A saúde é, então, } \\
\text { sinônimo de cidadania. }\end{array}$ & $\begin{array}{l}\text { A questão da alocação de recur- } \\
\text { sos passa por três perguntas: a } \\
\text { quem destiná-los? Quem decide? } \\
\text { Quais recursos e para quais ações? } \\
\text { Questiona-se se os recursos para } \\
\text { a saúde são inevitavelmente es- } \\
\text { cassos ou tal escassez é, na ver- } \\
\text { dade, apenas reflexo de escolhas } \\
\text { políticas. }\end{array}$ & $\begin{array}{l}\text { A adoção do princípio de equidade nas } \\
\text { políticas públicas de saúde não deve se } \\
\text { ater exclusivamente a considerações de } \\
\text { ordem econômica, mas buscar o bem- } \\
\text {-estar das pessoas, respeitando as dife- } \\
\text { renças entre elas e dando-lhes oportuni- } \\
\text { dades de se manifestarem e participarem } \\
\text { das decisões; que problemas da saúde } \\
\text { pública sejam abordados através de } \\
\text { ações direcionadas a partir da priorização } \\
\text { de demandas que partam dos cidadãos } \\
\text { menos favorecidos. }\end{array}$ \\
\hline $\begin{array}{l}\text { Garbois, Var- } \\
\text { gas e Cunha, } \\
2007\end{array}$ & $\begin{array}{l}\text { Descritiva com } \\
\text { abordagem } \\
\text { qualitativa, } \\
\text { com pesquisa } \\
\text { bibliográfica e } \\
\text { documental, e } \\
\text { com entrevista } \\
\text { semiestruturada }\end{array}$ & $\begin{array}{l}\text { As condições de vida da popu- } \\
\text { lação, problemas de saúde, de } \\
\text { acordo com as necessidades } \\
\text { de cada um e da coletividade. } \\
\text { Condições de acesso à habita- } \\
\text { ção, educação, renda, ao meio } \\
\text { ambiente, trabalho, transporte, } \\
\text { emprego, lazer, à liberdade, a } \\
\text { acesso e posse da terra e aces- } \\
\text { so a serviços de saúde. Padrões } \\
\text { dignos de qualidade de vida. }\end{array}$ & $\begin{array}{l}\text { A Estratégia Saúde da Família visa } \\
\text { reorientar o modelo de atenção à } \\
\text { saúde a partir da atenção básica, } \\
\text { em conformidade com os princí- } \\
\text { pios e diretrizes do SUS, mas não } \\
\text { consegue superar as iniquidades, } \\
\text { pois as necessidades de um } \\
\text { território nacional heterogêneo, } \\
\text { dos pontos de vista geopolítico, } \\
\text { econômico, cultural e social, e, } \\
\text { principalmente, nas grandes me- } \\
\text { trópoles, são pouco consideradas } \\
\text { no financiamento. }\end{array}$ & $\begin{array}{l}\text { Para concretizar o SUS, é preciso enfren- } \\
\text { tar a estruturação de um Estado capaz } \\
\text { de combater as profundas e gritantes } \\
\text { desigualdades sociais, na medida em } \\
\text { que elas expressam injustiça e exclusão } \\
\text { social. }\end{array}$ \\
\hline Lima, 2007 & $\begin{array}{l}\text { Revisão nar- } \\
\text { rativa }\end{array}$ & $\begin{array}{l}\text { Alocação de recursos adi- } \\
\text { cionais de custeio, que con- } \\
\text { templem diferentes perfis } \\
\text { demográficos, epidemiológicos } \\
\text { e condições sociossanitárias, e } \\
\text { que estejam orientados para as } \\
\text { realidades locorregionais. }\end{array}$ & $\begin{array}{l}\text { Não apresenta implicações para } \\
\text { o SUS. }\end{array}$ & $\begin{array}{l}\text { Não apresenta desafios relacionados à } \\
\text { aplicação no SUS. }\end{array}$ \\
\hline
\end{tabular}


Quadro 1. (cont.)

\begin{tabular}{|c|c|c|c|c|}
\hline Autores/Ano & Metodologia & $\begin{array}{l}\text { O que são 'necessidades } \\
\text { em(de) saúde'? }\end{array}$ & Implicações para o SUS & $\begin{array}{l}\text { Conclusões e desafios de sua aplicação } \\
\text { no SUS }\end{array}$ \\
\hline $\begin{array}{l}\text { Santos e } \\
\text { Gerschman, } \\
2004\end{array}$ & $\begin{array}{l}\text { Revisão nar- } \\
\text { rativa }\end{array}$ & $\begin{array}{l}\text { Não apresentam um conceito } \\
\text { sobre necessidades em saúde. }\end{array}$ & $\begin{array}{l}\text { Segmentação de clientelas, segun- } \\
\text { do lógicas de mercado (poder de } \\
\text { compra), com diferenciações não } \\
\text { só da qualidade, mas também do } \\
\text { tipo de serviço de saúde disponí- } \\
\text { vel, o que dificulta a operação das } \\
\text { necessidades em saúde. }\end{array}$ & $\begin{array}{l}\text { O caráter universalista do SUS parece } \\
\text { desacreditado nos grandes centros ur- } \\
\text { banos, onde a percepção do contraste } \\
\text { entre a qualidade do sistema público e a } \\
\text { do privado é muito grande. O padrão SUS } \\
\text { hoje parece estar caminhando no sentido } \\
\text { do 'plano de cuidados básicos', e já é evi- } \\
\text { dente uma segmentação público-privada, } \\
\text { que relega o SUS a produto de consumo } \\
\text { de circuitos inferiores. }\end{array}$ \\
\hline
\end{tabular}

Fonte: Elaboração própria.

Quadro 2. Polos de análise, núcleos de sentido, blocos de análise e referências dos artigos revisados, relacionados a cada núcleo/bloco. 2019

\begin{tabular}{lll}
\hline Polos de análise & Núcleo de sentido/Blocos de análise & Referências \\
\hline Necessidades em(de) Saúde & Direito social constituído & 18,21 \\
& Conjunto articulado da efetividade dos direitos sociais & 22,23 \\
& Ajuste entre as condições de vida e trabalho, com a & $19,20,24,25$ \\
& diversidade inerente às coletividades & \\
Implicações para o SUS & Capitalismo e sua crise & $8,11,13$ \\
& Financiamento & $13,14,17,21$ \\
& Características da formação social brasileira & $14,19,20$ \\
& Problemas da gestão pública na saúde & $11,15,17$ \\
& Mescla público-privado & 18,36 \\
& Problemas terminológicos & 11,12 \\
& Escassez de recursos & $14,23,39$ \\
Sesafios para a aplicação no SUS & Simbólico & 6 \\
& Crítico-político & $14,15,16,17$ \\
& Coerência entre financiamento e princípios & $11,13,19,23$ \\
& Estado & 20,21
\end{tabular}

Fonte: Elaboração própria. 


\section{Discussão}

Nos oito trabalhos ${ }^{18,23-25}$ em que as 'necessidades em(de) saúde’ são conceituadas, há a ideia geral de que a saúde não se restringe apenas às demandas biológicas, tampouco podem ser consideradas como individuais e isoladas ${ }^{26}$. De forma específica, pode-se dizer que o termo 'necessidades em(de) saúde' pode ser composto por três núcleos de sentido.

$\mathrm{O}$ primeiro relaciona o termo à ideia de 'direito social constituído'18,21. Para os autores, as necessidades em(de) saúde são: um direito social de cidadania e um conjunto integrado de ações de bem-estar e justiça social, ou, ainda, um conjunto de práticas democratizantes que integram a totalidade social, noção de direito à saúde que implica, entre outros fatores, a garantia de trabalho, alimentação, moradia, transporte, lazer e a participação da população na organização, na gestão e no controle dos serviços, além de acesso universal e igualitário em todos os níveis.

Sob essa ótica, é possível dizer que as necessidades em(de) saúde são expressões concretas, que devem conformar os alcances em que o direito à saúde deve se delinear. Mesmo considerando que a legislação infraconstitucional entende as necessidades de saúde como uma forma de guiar o financiamento ${ }^{27}$, há problemas em operacionalizá-la, especialmente quando se trata de um direito social, assim devendo, compulsoriamente, articular diversos elementos da vida social que fazem parte da múltipla determinação da saúde de coletividades e indivíduos ${ }^{28}$, como suposto nestas conceituações.

O segundo núcleo de sentido que compôs a ideia de necessidades em(de) saúde nesta revisão foi o do 'conjunto articulado da efetividade dos direitos sociais' ${ }^{22,23}$. Neste sentido, o termo encerra sua semelhança nos seguintes significados: condições de alimentação, habitação, educação, renda, meio ambiente, transporte, emprego, lazer, liberdade, acesso e posse da terra, e acesso a serviços de saúde ou, em outras palavras, alimentar-se adequadamente, ter condições dignas de moradia, direito ao trabalho e horas de lazer.

Nesse núcleo de sentido, seu conteúdo corrobora a afirmação anterior. Contudo, a ênfase nesse núcleo de sentido recaiu sobre os critérios 'social' e 'efetivo'. Quando se pensa a saúde como fenômeno socialmente determinado, o enfoque deve ser orientado mais ao 'social articulado' do que ao seu significado isolado. Isto força o direito a se dilatar para congregar a amplitude do que significa garantir saúde, o que, como já sabido ${ }^{24}$, transcende o próprio setor. No que se refere à efetividade do direito, as necessidades significam a operação deste na vida concreta dos indivíduos, que, em suas situações cotidianas, devem acessar os serviços em função de uma ação estatal proativa, e não o seu contrário.

O terceiro núcleo de sentido $\mathbf{1 9 , 2 0 , 2 4 , 2 5}$ converge ao rebuscar o termo, tentando maior precisão analítica. Neste caso, 'necessidades em(de) saúde' se relaciona ao 'ajuste entre as condições de vida e trabalho com a diversidade inerente às coletividades'. Assim, dizem que são: necessidades diferentes entre os distintos grupos sociais, tanto determinadas pela diversidade de sexo, idade e raça quanto por situações de injustiça social, como renda e acesso a bens e serviços, e, ainda, por características culturais e subjetivas de grupos e indivíduos ou condições de vida da população, problemas de saúde de acordo com as necessidades de cada um e da coletividade. Condições de acesso à habitação, educação, renda, ao meio ambiente, trabalho, transporte, emprego, lazer, à liberdade, ao acesso e à posse da terra, e ao acesso a serviços de saúde, ou ainda, a padrões dignos de qualidade de vida.

É interessante perceber que, neste sentido, o 'ajuste' é o mais importante e, talvez, o mais desafiador. Mesmo quando se tenta considerar a imensa diversidade de 'necessidades em(de) saúde', dos mais variados grupos populacionais, isto exige uma acomodação da oferta em função das necessidades, e não o contrário $^{24}$. Pressiona, certamente, que toda a cadeia entre modelo e gestão de serviços atue em um 
movimento de diagnóstico e planejamento local, em direção ao nacional (ascendente) ${ }^{25}$, que, em termos concretos, tem sido visto apenas como figura de retórica ${ }^{29} \mathrm{em}$ alguns textos jurídicos, como mais uma letra morta ${ }^{30}$ ou, quando muito, em experiências pontuais ${ }^{31}$.

Esse sentido ainda traz à tona a discussão da saúde coletiva sobre as necessidades, do ponto de vista de sua heterogeneidade. Tais necessidades se originam da reprodução da vida em sociedade e devem estar articuladas entres $\mathrm{si}^{\mathbf{3 2}}$. Nos textos, é possível perceber como valorizar o conhecimento e a forma como os sujeitos estão inseridos na reprodução social, requerendo a compreensão da realidade, simultaneamente objetiva às concepções subjetivas que se manifestam dos indivíduos, identificando-se os diferentes significados atribuídos a seus modos de vida, saúde e sofrimento, o que pode revelar o potencial transformador das práticas de saúde vigentes ${ }^{33}$. Ainda outro aspecto importante deste último sentido se deve ao fato de que ele cita a qualidade de vida como uma 'dimensão' da necessidade. Ora, em que pese a interpenetração de todos estes conceitos na realidade concreta, é necessária a definição precisa sobre qual conceito está subjacente ao outro ${ }^{34}$, podendo este elemento ser mais um desafio na concretização das necessidades em(de) saúde enquanto medida.

Em relação às implicações, para o SUS, dos estudos sobre as necessidades em(de) saúde, estes apresentam uma gama variada de implicações, que podem ser compiladas em sete blocos. Mesmo sabendo que todas as implicações para o SUS estão intimamente ligadas, inclusive com seus desafios, é possível agrupá-las pelas semelhanças em que são citadas.

O primeiro bloco de implicações mais frequente é aquele que aponta para o 'capitalismo e sua crise'. Assim, os estudos indicam que a implicação mais forte sobre a não concretização das necessidades em(de) saúde é o caminho percorrido entre os efeitos diretos da crise contemporânea do capitalismo, que impacta na não efetivação do direito à saúde em função do pagamento de juros e da amortização da dívida pública. Aponta-se, ainda, que a financeirização dos recursos públicos, através do grande capital financeiro, é o responsável pela apropriação do fundo público, servindo de forma de acumulação e reprodução do capital13. Isto se reflete mediante a decisão política de realizar cortes nos recursos para a área social, a diminuição dos gastos com os direitos sociais, dos quais a saúde é um deles, não contemplando as necessidades ${ }^{8}$. Apesar da recessão econômica e do SUS, o que se observa é a não retração do mercado dos planos de saúde. Isso seria esperado caso o SUS estivesse oferecendo produtos comparáveis aos oferecidos pelos planos, o que não é observado, criando a possibilidade de crescente focalização da oferta no sistema público, afastando-se da necessidade em(de) saúde em sua concepção"1.

Ao mesmo tempo em que a Reforma Sanitária Brasileira veio como ponto de apoio para a redefinição radical das políticas públicas, revela-se também como fonte de enormes tensionamentos e conflitos ao se confrontar com a realidade do acelerado processo de mercantilização da saúde como tendência mundial. No Brasil, este movimento se expressa no crescimento rápido do sistema privado de saúde, no qual vem se firmando como fonte para uma acumulação de capital que cria as necessidades de acordo com o mercado ${ }^{35}$.

As crises de acumulação têm levado o capital a expandir-se para todos os espaços da vida social, entre eles, a saúde, transformando-a em esfera de valorização deste mesmo capital. Através das orientações do Banco Mundial, reafirma-se que o mercado é central como mecanismo organizador da vida social, cujos gestores devem ver as formas mais 'eficientes' (economicamente) de operar as políticas públicas. Há uma ressignificação do papel da necessidade neste debate ${ }^{6}$, que deixa de ser a necessidade dos trabalhadores para se converter, cada vez mais, na necessidade de acumular do capital.

O segundo bloco das implicações se refere 
exclusivamente ao problema do 'financiamento'. O subfinanciamento do SUS é algo crônico, em virtude das políticas de ajuste fiscal sucessivamente adotadas ${ }^{\mathbf{1 4}}$. Mesmo a aprovação de uma fonte de financiamento específica para a saúde, em um momento subsequente (a Contribuição Provisória sobre Movimentação Financeira (CPMF), em 1996), não assegurou o aumento substantivo e a estabilidade de recursos para o setor ${ }^{\mathbf{2 1}}$.

Diante da predominância de políticas macroeconômicas restritivas adotadas pelos governos federais, a partir dos anos 1990, conciliado ao capitalismo contemporâneo, o percurso do financiamento da seguridade social permaneceu sob forte tensão ${ }^{17}$. Por um lado, destaca-se o princípio da construção da universalidade, por meio da defesa permanente de recursos financeiros seguros e, por outro lado, identifica-se o princípio da contenção de gastos, uma reação defensiva que se articula em torno da defesa da racionalidade econômica $^{13}$, além dos incentivos concedidos pelo governo federal à saúde privada, com redução de imposto de renda a pagar pela pessoa física ou jurídica, e as renúncias fiscais que experimentam as entidades sem fins lucrativos e a indústria farmacêutica ${ }^{17}$ demonstram que a necessidade que se contempla é a do capital e não a da saúde da população. Em última instância, é o Estado criando o mercado para o setor privado como medida para 'desafogar' a demanda do SUS e manter o seu desfinanciamento ${ }^{\mathbf{1 4}}$.

O terceiro bloco das implicações se refere às 'características da formação social brasileira'. Para os autores ${ }^{\mathbf{1 4 , 1 9 , 2 0}}$, as dificuldades impostas por um Estado patrimonialista, conservador, avesso a quaisquer medidas de distribuição mais equitativa dos recursos sociais, mesmo que modesta, são implicações importantes na desconsideração das necessidades, já que o direito universal à saúde não faz parte do ideário (proto)liberal constitutivo desta sociedade. Além disto, superar as iniquidades que se alastram ao longo da história e acumulam hoje uma dívida social, bem como a pobreza massiva que leva à dependência em relação aos serviços prestados pelo Estado, além das desigualdades em saúde que permanecem na sociedade, $\mathrm{e}$ conseguir operacionalizar as necessidades em um território nacional heterogêneo aparecem como grandes dificuldades ${ }^{20}$. Esta observação tem sido considerada importante na formulação de políticas públicas, na lida com a noção de necessidades diferentes entre os distintos grupos sociais, além de situações de injustiça social e características culturais e subjetivas de grupos e indivíduos ${ }^{19}$.

O quarto bloco das implicações se refere aos 'problemas da gestão pública na saúde'. Desde a criação do SUS, houve melhora na condição de saúde da população brasileira, contudo, dois problemas persistem, impedindo a continuidade de seu avanço: a dificuldade de acesso e o problema de financiamento ${ }^{\mathbf{1 7}}$. No setor público, verifica-se uma diferenciação negativa na qualidade dos serviços, com aumento da restrição do acesso a produtos de maior complexidade, fragilidades nos processos regulatórios, longo tempo de espera em filas para o atendimento, deficiência de recursos físicos e materiais, e insuficiente provisão de insumos relevantes para a saúde. Isto se agudiza quando há a percepção do contraste da qualidade do sistema público em relação ao privado, gerando um descrédito da população em relação ao SUS. A mídia, de forma muito intensa, reforça esta percepção, construindo uma segmentação que relega o SUS a produto de consumo de circuitos inferiores, em que a percepção de simplificação da oferta pública, aliada a dificuldades de acesso, vem contribuindo para a adesão da população às necessidades do capital, especialmente expressas no crescimento dos planos de saúde ${ }^{\mathbf{1 1}, 15}$.

Segundo o Banco Mundial, a governança é um problema crucial no SUS, em todos os níveis de governo, pela baixa capacidade local para gerenciar responsabilidades descentralizadas, pela falta de inovação nos modelos organizacionais e de gestão ${ }^{6}$. Os recursos disponíveis são escassos e há uma pobreza massiva que leva à dependência em relação aos serviços prestados pelo Estado, fazendo com que os resultados da 
alocação tenham impactos muito relevantes na vida dos cidadãos. Contudo, a questão da alocação de recursos passa pelas seguintes perguntas: a quem destiná-los? Quem decide sobre eles? Quais recursos e para quais ações? Os recursos para a saúde são inevitavelmente escassos ou tal escassez é, na verdade, apenas reflexo de escolhas políticas? Em uma sociedade onde o lucro domina as prioridades de pesquisa, a abordagem preventiva dos sistemas de assistência à saúde torna-se gradativamente uma parte mínima ${ }^{23}$.

O quinto bloco das implicações refere-se à 'mescla público-privado', que permeia a organização da atenção à saúde no SUS. Para os autores, a diferenciação não só da qualidade, mas também do tipo de serviço de saúde disponível expressa este processo de múltiplas articulações entre o público e o privado, que consolidou uma realidade muito distante da preconizada pelo projeto da Reforma Sanitária Brasileira $^{\mathbf{1 8}}$. O direito universal à saúde não faz parte do ideário liberal e também não é mencionado nos princípios filosóficos do Banco Mundial, sendo a saúde considerada um bem de consumo que deveria ser oferecido pelo mercado, este que, supostamente, melhor organizaria a produção, a distribuição e mesmo o consumo, tendo a intervenção do Estado somente para regular a oferta e garantir mínimos essenciais ${ }^{6}$. Com uma frequência cada vez maior, pode-se observar o desabastecimento de produtos importantes para o SUS, tendo como justificativa vários motivos relacionados à tênue relação existente entre as necessidades de saúde pública e as lógicas de mercado ${ }^{36}$, introduzindo dispositivos que aumentem a participação do usuário no custeio das ações e serviços de saúde.

Assim, o que se pôde observar na Reforma Sanitária Brasileira, no decorrer dos anos, foi uma confluência perversa entre um projeto político democratizante e participativo e o modelo neoliberal, que tem prevalecido na gestão do sistema. Deste modo, tornar-se cidadão passa a significar a integração individual ao mercado, como consumidor e como produtor ${ }^{\mathbf{8}, 37}$, sendo a parceria público-privada a nova forma de manifestação dessa política, justificada como a racionalização do uso dos recursos, gerando organizações de custo administrativo alto, obrigatoriedade de pagamento dos serviços pela população, negligência pelo sistema dos determinantes sociais e econômicos da saúde, estímulo à competição entre serviços e sua distribuição orientada por doenças e intervenções específicas, que não necessariamente estão relacionadas às necessidades em saúde das populações, mas são influenciadas por interesses privados ${ }^{\mathbf{1 8 , 3 8}}$.

O sexto bloco sugere 'problemas terminológicos'. Na contramão das propostas universalizantes do SUS, vem se acentuando uma tendência à segmentação de clientelas, segundo lógicas de mercado (poder de compra), com diferenciações não só da qualidade quanto do tipo de serviço de saúde disponível'11. Neste caminho, pode-se pensar que a 'nova universalidade' compreende uma cesta básica de serviços para a população pobre, restando o acesso aos demais serviços de saúde pela via do mercado. Isto convertendo o acesso universal enquanto direito social, em uma cobertura universal de saúde onde não é o 'acesso' em função das 'necessidades em(de) saúde' que está no centro da questão, mas sim, o que o orçamento público comprometido e com restrições orçamentárias pode ofertar, além da quantidade de serviços cobertos que podem ser ofertados e consumidos pelo mercado ${ }^{12}$.

O sétimo bloco das implicações, este minoritário, trata da 'escassez de recursos' no SUS. Pode-se dizer que a restrição acentuada dos recursos no financiamento da saúde foi consolidada pela Emenda Constitucional $n^{0}$ $95 / 2016^{39}$, que instituiu um teto congelado para os gastos públicos, nas funções saúde e educação, por $20 \operatorname{anos}^{\mathbf{1 4}}$. O problemático dilema da escassez de recursos para a saúde e a necessidade de alocá-los de forma justa para todos se traduzem nos três princípios morais e políticos norteadores do SUS, que preconizam: a 'universalidade' de acesso aos serviços de saúde (art. 196); a 'integralidade’ 
(art. 198., Inc. II); e a 'igualdade' na assistência à saúde para todos (art. 196). Porém, esta ideia parece ser, no mínimo, contraditória, quando se pensa em distribuição justa de recursos com um sistema de saúde que ignora as desigualdades, e quando se questiona se o grande problema é a escassez de recursos ou a falta de comprometimento político com o destino dado às verbas existentes ${ }^{23}$.

Por fim, quais os principais desafios da aplicação do SUS no que se refere às necessidades em(de) saúde? Ao integrar os resultados encontrados nesta revisão, podem ser classificados sete tipos de desafios que impactam na compreensão ou operacionalização das necessidades. Do mais teórico ao mais prático, tem-se que o primeiro deles, o 'simbólico'6, reforça que o SUS deve ser um exemplo para outros países da América Latina, algo que não tem tido força suficiente. Já o desafio 'crítico político'14-17 reside no amálgama entre um olhar crítico e denso sobre o conflituoso caminho de consolidação do direito à saúde, mobilizando os segmentos da sociedade e criando espaços de discussão dos principais aspectos que dificultam a consolidação do SUS, tendo como norte a concepção da radicalidade necessária para operar esse projeto, considerando-o como uma utopia a ser perseguida ao desconsiderar as negociações pragmáticas da gestão e das políticas públicas. Para isto, o desafio da 'coerência entre financiamento e princípios' ${ }^{\prime 11,13,19,23}$ ganha centralidade, especialmente na concretude da universalidade e da equidade.

Saindo da perspectiva teórica e indo para a prática, o desafio de lidar como o 'Estado'20,21 é crucial. Sem uma clara compreensão, segundo os autores, do seu papel na garantia da democracia, com sua função mediadora de interesses e demandas, é difícil combater as profundas e gritantes desigualdades sociais, pois estas se relacionam diretamente com as necessidades. $\mathrm{O}$ desafio da 'política macroeconômica'8,18 também está dado como o centro da discussão, para alguns autores. $\mathrm{O}$ foco desta política tem de ser a equalização do crescimento econômico, mantendo o patamar de investimento em políticas sociais, não admitindo que o Estado se isente de seu papel na efetivação dos direitos sociais.

Entre os desafios mais aplicados, aqueles relacionados à 'gestão' 15,22 têm parcela no desuso das necessidades como guias para uma ação sanitária. Para alguns estudos, o centro do debate é a definição, de forma clara, das responsabilidades sanitárias e do papel das esferas de governo, evitando a privatização dos serviços por meio das 'novas' modalidades de gestão propostas para o serviço público, que descaracterizam uma atenção com base nas necessidades. E, por fim, o desafio do 'âmbito local'12,18 na execução das políticas. Para alguns autores, o desafio central está no avanço da descentralização das decisões e na prerrogativa de que estas precisam construir sistemas locais que funcionem solidariamente, para darem conta das necessidades de sua região.

Mesmo sob a diversidade de elementos que este estudo apresenta, a integralização de tais resultados padece de algumas limitações. Entre elas, a captura e análise das 'necessidades em(de) saúde' como objeto em questão já é um desafio em si mesmo. Algumas vezes descrita de forma subliminar ou, ainda, como consequência dos serviços (e não como foco), demonstra como o terreno sob esse tema é espinhoso e tem mais assento em um consenso não dito do que uma delimitação clara sobre o que significam tais necessidades. Além disto, o uso de uma revisão do tipo integrativa, apesar de demonstrar um panorama sobre o objeto, tem como limite não focar essencialmente no objeto per si, já que visa integrar tudo que com o objeto se relacione de forma direta. Isto pode ser visto no fato de alguns artigos incluídos na revisão não apresentarem diretamente seu conceito sobre necessidades, mas explicitarem implicações e desafios sobre o alcance destas. É plausível dizer que a presente revisão pode ser encarada como uma primeira sistematização metódica mais ampla sobre o tema ${ }^{3}$, com uso de um método claramente delineado para isto. Para avançar, sugere-se que, em estudos 
posteriores, outros métodos de revisão possam ser utilizados, assim como uma ampliação para outras bases de dados possa ser efetivada.

Após ponderadas as limitações deste estudo, é fundamental apontar que suas possibilidades são essenciais para garantir a precisão da categoria necessidades, e sua devida operacionalidade no SUS. Trazer este debate à baila é também garantir a visibilidade política do tema, tão esquecido nos ditames das decisões político-administrativas e do cotidiano dos serviços do sistema de saúde brasileiro. Em tempos de crise econômica de largo espectro como a vivenciada atualmente, trabalhar as ações de serviços com foco nas necessidades de saúde é também economizar recursos, acomodar a oferta à demanda e, certamente, efetivar os princípios do SUS em sua essência.

\section{Considerações finais}

De acordo com o exposto acima, fica evidente que o termo 'necessidades em(de) saúde' ainda está longe de ser compreendido e utilizado de forma acordante entre os que atuam nos sistemas de saúde. Se, por um lado, observam-se a defesa dos direitos universais de saúde e a ampliação da integralidade e equidade para um atendimento mais abrangente, com respostas às necessidades em(de) saúde de cada cidadão, em cada território, pensando em suas diferenças, como um conjunto de práticas democratizantes que integram a totalidade social, por outro lado, é necessário o atendimento a 'outras necessidades', relacionadas à mercantilização da saúde de forma ostensiva, em que 'cidadania' se confunde com 'poder de consumir' e 'necessidades em(de) saúde' se resumem ao consumo de um serviço ou procedimento de saúde.

Nesse cenário, as implicações para o SUS são imensas e, somadas a um subfinanciamento crônico e a políticas restritivas adotadas pelos governos federais, o resultado não poderia ser outro: mais desajuste social, com desemprego, violência e piora das condições de vida e de saúde da sociedade, abrindo espaço cada vez maior para as práticas privatistas que surgem no interior do sistema público.

Consequentemente, o desafio de ofertar um SUS baseado em necessidades em(de) saúde, com alocação de recursos de forma equitativa e igualitária, e qualidade no acesso à saúde, se torna cada vez maior. Com um movimento permanente e contraditório de contenção de gastos, o que se assiste é um processo de apropriação privada da saúde e a disputa entre dois grandes projetos antagônicos na saúde, cuja necessidade que continuamente vem sendo assistida é a do capital.

É nessa realidade de desmonte dos direitos sociais que se faz necessário o resgate do protagonismo do movimento social pela saúde, tornando-se imprescindível construir uma vontade coletiva de mobilização pela saúde, buscando democratizar a consciência sanitária, enfrentando coletivamente a onda conservadora do mercado e efetivando a saúde como um direito público e não como mera mercadoria. Investir na superação dos desafios elencados por este artigo pode ser um guia nesta empreitada.

\section{Colaboradores}

Carnut L (0000-0001-6415-6977)* trabalhou para a concepção, delineamento, método, análise e interpretação dos dados, assim como para a revisão final do texto para publicação. Ferraz CB (0000-0003-4460-4095)* trabalhou para a redação e qualificação do projeto, coleta e análise dos dados, e para a redação final. 


\section{Referências}

1. Gomes Júnior NN, Pereira PAP. Necessidades do capital versus necessidades humanas no capitalismo contemporâneo: uma competição desigual. Argumentum. 2013; 5(1):50-65.

2. Cecílio LCO. As Necessidades de Saúde como Conceito Estruturante na Luta pela Integralidade e Equidade na Atenção em Saúde. In: Pinheiro R, Mattos RA. Os sentidos da integralidade na atenção e no cuidado à saúde. Rio de Janeiro: IMS; Abrasco; 2001. p. 113-126.

3. Campos CMS, Bataiero MO. Health needs: an analysis of Brazilian scientific literature from 1990 to 2004. Interface - Comunic., Saúde, Educ. 2007; 11(23):605-18.

4. Almeida FN, Paim JS. Saúde coletiva: uma "nova saúde pública” ou campo aberto a novos paradigmas? Rev. Saúde Pública, 1998; 32(4):299-316.

5. Brasil. Constituição, 1988. Constituição da República Federativa do Brasil. Brasília, DF: Senado Federal: 1988.

6. Rizzotto MLF, Campos GWS. O Banco Mundial e o Sistema Único de Saúde brasileiro no início do século XXI. Saúde Soc. 2016; 25(2):263-276.

7. Rizzotto MLF. Capitalismo e saúde no Brasil nos anos 90: as propostas do Banco Mundial e o desmonte do SUS. São Paulo: Hucitec; 2012.

8. Mendes A. A Saúde Pública brasileira no contexto da crise do Estado ou do Capitalismo? Saúde e Soc. 2015; 24 (supl1):66-81.

9. Mendes KDS, Silveira RCCP, Galvao CM. Revisão integrativa: método de pesquisa para a incorporação de evidências na saúde e na enfermagem. Texto contexto - enferm. 2008; 17(4):758-764.

10. Ercole FF, Melo LS, Alcoforado, CLGC. Revisão integrativa versus revisão sistemática. Reme. 2014; 18(1):1260.

11. Santos MAB, Gerschman S. As segmentações da oferta de serviços de saúde no Brasil - arranjos institucionais, credores, pagadores e provedores. Ciênc. Saúde Colet. 2004; 9(3):795-806.

12. Mendes A, Louvison M. O debate da regionalização em tempos de turbulência no SUS. Saúde Soc. 2015; 24(2):393-402.

13. Mendes A, Marques RM. O financiamento do SUS sob os "ventos" da financeirização. Ciênc. Saúde Colet. 2009; 14(3):841-850.

14. Cohn A. "Caminhos da reforma sanitária", revisitado. Estudos Avançados. 2018; 32(93):225-241.

15. Miranda GMD, Mendes ACG, Silva ALA. O desafio da organização do Sistema Único de Saúde universal e resolutivo no pacto federativo brasileiro. Saúde Soc. 2017; 26(2):329-335.

16. Merhy E. Saúde e Direitos: tensões de um SUS em disputa, molecularidades. Saúde Soc. 2012; 21(2):267279.

17. Mendes A. Direito como instrumento de efetivação (ou não) do direito à saúde no Brasil - Cenário dos desafios ao direito à saúde universal brasileira. R. Dir. sanit. 2013; 14(2)113-118.

18. Silva HFS, França Júnior I. A combinação de projetos políticos distintos na atenção básica à saúde: impactos político-sociais e a desconstrução do SUS. Physis Rev Saúde Colet. 2015; 25(2):423-442.

19. Barros FPC, Sousa MF. Equidade: seus conceitos, significações e implicações para o SUS. Saúde Soc. 2016; 25(1):9-18.

20. Garbois JA, Vargas LA, Cunha FTS. O Direito à Saúde na Estratégia Saúde da Família: uma Reflexão Necessária. Physis Rev Saúde Colet. 2008; 18(1):27-44.

21. Baptista TWF, Machado CV, Lima LD. Responsabilidade do Estado e direito à saúde no Brasil: um balanço da atuação dos Poderes. Ciênc. Saúde Colet. 
2009; 14(3):829-839.

22. Araújo IMM. Direito à Saúde: aspectos do modelo neodesenvolvimentista brasileiro e da privatização da saúde. R. Dir. sanit. 2015; 16(1):128-145.

23. Gonçalves ER, Albuquerque GL, Aerdmann AL, et al. Reflections on equality, justice and allocation of resources in health: the bioethical point of view to the inequitable society's dilemmas. Online Brazilian Journal of Nursing. 2007; 6(2).

24. Lima LD. Conexões entre o federalismo fiscal e o financiamento da política de saúde no Brasil. Ciênc. Saúde Colet. 2007; 12(2):511-522.

25. Pinto HA. Análise do financiamento da Política Nacional para a Atenção Básica de 1996 até 2017. Saúde em Redes. 2018; 4(1):35-53.

26. Breilh J. Epidemiologia e economia, política e saúde. São Paulo: Hucitec; 1991.

27. Brasil. Ministério da Fazenda. Lei Complementar $\mathrm{n}^{\mathrm{o}}$ 141, de 13 de janeiro de 2012. Regulamenta valores mínimos em ações e serviços públicos de saúde. Diário Oficial União. 16 Jan 2012.

28. McKeown T, Lowe CR. Introducción a la Medicina Social. México: Siglo Veintiuno; 1981.

29. Baldani MH, Fadel CB, Possamai T, et al. A inclusão da odontologia no Programa Saúde da Família no Estado do Paraná. Cad. Saúde Pública. 2005; 21(4):1026-1035.

30. Brasil. Ministério da Saúde. Portaria no 2.135 , de 25 de setembro de 2013. Estabelece diretrizes para o processo de planejamento no âmbito do Sistema Único de Saúde (SUS). Diário Oficial da União. 26 Dez 2005

31. Rueda MEBM, Nunes CLMT. Planejamento ascendente e participativo: prática adotada na Secretaria Municipal de Saúde de Bauru. Saúde Soc. 2009; 18(supl1):73-74.

32. Barros DG, Chiesa AM. Autonomia e necessidade de saúde na Sistematização da Assistência de Enferma- gem no olhar da saúde coletiva. Rev Esc Enferm USP. 2007; 41(esp):793-8.

33. Nakamura EE, Egry EY, Campos CMS, et al. O potencial de um instrumento para o reconhecimento de vulnerabilidades sociais e necessidades de saúde: saberes e práticas em saúde coletiva. Rev Lat Am Enferm. 2009; 17(2):253-8.

34. Fleck MPA. O instrumento de avaliação de qualidade de vida da Organização Mundial da Saúde (WHOQOL-100): características e perspectivas. Ciênc. Saúde Colet. 2000; 5(1):33-38.

35. Elias PE. Estado e Saúde os desafios do Brasil contemporâneo. São Paulo em Perspectiva. 2004; 18(3):4146.

36. Rezende KS. Produção: a corda bamba entre o mercado e as necessidades de saúde pública. 2016. [acesso em 2020 fev 9]. Disponível em: https://www.paho.org/bra/index.php?option=com docman\&view=download $\&$ alias $=1532$-producao-a-corda-bamba-entre-o-mercado-e-as-necessidades-saude-publica-2\&category_slug=serie-uso-racional-medicamentos-284\&Itemid=965.

37. Dagnino E. Sociedade civil, participação e cidadania: de que estamos falando. In: Mato D., editor. Políticas de Ciudadanía y Sociedad Civil en tiempos de globalización. Caracas: FaCES, Universidad Central de Venezuela, 2004.

38. Maciocco G, Stefanini A. From Alma-Ata to the global fund: the history of international health policy. Rev. Bras. Saúde Matern. Infant. 2007; 7(4):479-486.

39. Brasil. Congresso Nacional. Emenda Constitucional $\mathrm{n}^{\circ}$ 95, de 15 de dezembro de 2016. Altera o Ato das Disposições Constitucionais Transitórias, para instituir o Novo Regime Fiscal, e dá outras providências. Diário Oficial da União. 16 Dez 2016.

Recebido em 16/03/2020

Aprovado em 28/01/2021

Conflito de interesses: inexistente

Suporte financeiro: não houve 